\title{
Selective Enhancer of Tumor Vascular Permeability for Optimization of Cancer Chemotherapy
}

\author{
Yasuo Yoshioka, Yasuo Tsutsumi, ${ }^{*}$ Haruhiko Kamada, Tetsuya Kinira, Shin-ichi Tsunoda, \\ Yoko Yамамото, Takayuki Oкамото, Hiroko Shibata, Yohei Mukai, Madoka TaniaI, \\ Tomoe Shimizu, Maki Kawamura, Yasuhiro Abe, Shinsaku NAKAgawa, and Tadanori Mayumi \\ Department of Biopharmaceutics, Graduate School of Pharmaceutical Sciences, Osaka University; 1-6 Yamadaoka, Suita, \\ Osaka 565-0871, Japan. Received October 14, 2003; accepted December 9, 2003
}

Clinical approach using tumor necrosis factor-alpha (TNF- $\alpha$ ) as selective destruction against tumor endothelial cells and selective enhancer of tumor vascular permeability for effective accumulation of antitumor chemotherapeutic agents has attracted attention. However, the clinical application of TNF- $\alpha$ as a systemic antitumor agent has been limited because of toxic side-effects. To systemically use TNF- $\alpha$ as an antitumor agent and the selective enhancer of tumor vascular permeability, we assessed the usefulness of PEGylated TNF- $\alpha$ (PEGTNF- $\alpha$ ). PEG-TNF- $\alpha$ at a dose of 1000 JRU showed marked hemorrhagic necrosis in S-180 tumors without sideeffects due to selective destruction of tumor vasculature, whereas wild-type TNF- $\alpha$ at a dose of 10000 JRU showed a little hemorrhagic necrosis with severe side-effects. PEG-TNF- $\alpha$ induced the enhancement of tumor vascular permeability. The permeability was increased at $1 \mathrm{~h}$, after an i.v. injection of PEG-TNF- $\alpha$ and returned to the basal level at $2 \mathrm{~h}$. In addition, high molecular weight of PEG (molecular weight; 500K) accumulated in tumor tissue as well as low molecular weight of PEG (molecular weight; 12K). On the other hand, PEG-TNF- $\alpha$ didn't affect the permeability of normal tissue and inflammation site. This data suggested that PEG-TNF- $\alpha$ was useful agent as selective enhancer of tumor vascular permeability with safe.

Key words tumor necrosis factor-alpha; permeability; tumor endothelial cell; chemotherapeuctic drug

With the development of tumor biology, molecular biology, and combinatorial chemistry, many therapeutic agents have been developed for tumors. However, the clinical application of antitumor agents such as cytokines, antibodies and chemotherapeutic drugs has failed because of poor accumulation in the tumor tissue. ${ }^{1,2)}$ Heterogeneous tumor perfusion, vascular permeability, and increased interstitial pressure restricted the penetration of therapeutic agents into tumor tissue from circulation. ${ }^{1,2)}$

It has been suggested that tumor necrosis factor-alpha (TNF- $\alpha$ ) can overcome these problems. TNF- $\alpha$ was identified as a cytokine that specifically injures tumors and has been highlighted as a potent anti-tumor agent. ${ }^{3)}$ Furthermore, TNF- $\alpha$ destroyed the tumor vasculature selectively and enhanced the tumor vascular permeability. ${ }^{4}$ Regional isolated limb perfusion using TNF- $\alpha$ in combination with melphalan or doxorubicin showed greater therapeutic effects on softtissue sarcoma or melanoma than chemotherapeutic drugs alone. ${ }^{5)}$ It is believed that the synergistic effect between TNF- $\alpha$ and chemotherapeutic drugs results from TNF- $\alpha$-induced destruction of tumor vasculature and enhancement of tumor vasculature permeability. However, because of its high instability and pleiotropic action in vivo, attempts to use TNF- $\alpha$ as a systemic anticancer agent and an enhancer of tumor vascular permeability in humans, failed due to severe systemic side effects such as fever and decreased blood pressure as seen in case of an endotoxin-like shock, before therapeutic doses could be administered. ${ }^{6}$

To overcome these drawbacks and apply TNF- $\alpha$ as a systemic administrator, we have attempted to conjugate TNF- $\alpha$ with polyethylene glycol (PEG) and other water-soluble polymeric modifiers. $^{7-10)}$ We showed that the antitumor effects of PEG-TNF- $\alpha$, obtained by PEGylation with a molecular weight of 5000, was enhanced to 100 times that of unmodified TNF- $\alpha$, without increasing their toxic side ef- fects. ${ }^{7,8)}$ In this study, we examined the usefulness of PEGTNF- $\alpha$ as a selective enhancer of tumor vascular permeability. We showed that PEG-TNF- $\alpha$ enhanced the permeability of tumor vasculature without having any effect on the permeability of normal tissue. We considered that PEG-TNF- $\alpha$ would be used with chemotherapeutic drugs for tumor therapy.

\section{MATERIALS AND METHODS}

Preparation of ${ }^{125}$ I-Labeled Polymers Radiolabeled polymeric modifiers were prepared by the chloramine-T method. PEGs (average molecular weight: 12000, 50000, 70000,500000 ) (purchased from Wako Pure Chemical Industries, Ltd., Osaka, Japan) dissolved in 1,4-dioxan were reacted with $N, N^{\prime}$-carbonyldiimidazole for $6 \mathrm{~h}$ at room temperature. After dialysis in water, the activated polymers were reacted with a 2-fold molar excess of thyramine hydrochloride for $48 \mathrm{~h}$ at $4{ }^{\circ} \mathrm{C}$. These reaction mixtures were also dialyzed in water and lyophilized. The polymer-thyramine conjugates, dissolved in a $0.4 \mathrm{M}$ sodium phosphate buffer $(2.5 \mathrm{mg} / \mathrm{ml})$ and $\mathrm{Na}^{125} \mathrm{I}(100 \mathrm{mCi} / \mathrm{ml})$, were mixed in a microcentrifuge tube on ice. The labeling reaction was started by the addition of $3.8 \mathrm{~mm}$ chloramine T. After iodination, the reaction was stopped by the addition of $2.5 \mathrm{~mm}$ sodium pyrosulfate. ${ }^{125} \mathrm{I}-$ Labeled polymer was purified by Gel Filtration Chromatography on the Econo-Pac ${ }^{\circledR} 10 \mathrm{DG}$ column.

In Vivo Behavior of Polymers All experimental protocols for animal studies were in accordance with the Guide for Laboratory Animal Facilities and Care (NIH publication 8523, rev 1985). These protocols have been approved by the committee of the Pharmaceutical School, Osaka University, Japan. PEG-TNF- $\alpha$, in which $56 \%$ of the lysine amino groups of natural human TNF- $\alpha$ (Hayashibara Biological Laboratories Inc., Okayama, Japan) were coupled with PEG 
and prepared as described. ${ }^{7)} \mathrm{S}-180$ cells were implanted intradermally $\left(5 \times 10^{5}\right.$ cells $/ 200 \mu \mathrm{l} /$ site $)$ in 5 -week-old female $\mathrm{BALB} / \mathrm{c}$ mice. On day 7 , when the tumor diameter reached $7 \mathrm{~mm}$, PEG-TNF- $\alpha$ [500 Japan Reference Unit (JRU)/ mouse] was injected i.v. into the mice. At 1, 1.5, 2, 3, 4, and $6 \mathrm{~h}$ later, various molecular weight of ${ }^{125} \mathrm{I}$-Labeled PEG $\left(1 \times 10^{6} \mathrm{cpm} / 200 \mu \mathrm{l}\right)$ were administered i.v. Thirty minutes after the injection of ${ }^{125} \mathrm{I}$-Labeled PEG, the mice were killed by abdominal arterial exsanguination. Then, the liver, kidney, spleen, heart, lungs, brain, inflammatory sites in which cotton had been implanted, skin and tumor were recovered and their radioactivity was measured by a $\gamma$-counter. The vascular permeability (VP) ratio was calculated according to the following equation.

VP ratio
$=\frac{\text { the radioactivity of tissue after the administration of PEG-TNF }-\alpha}{\text { the radioactivity of tissue without the administration of PEG-TNF }-\alpha}$

\section{RESULTS AND DISCUSSION}

Recently, TNF- $\alpha$ has been clinically applied to loco-regional combination therapy with Melphalan, and this therapy showed a marked antitumor effect for patients in transit melanoma metastases. ${ }^{11)}$ This clinical approach, using TNF$\alpha$ as a selective destruction agent against tumor endothelial cells and as a selective enhancer of tumor vascular permeability for effective accumulation of antitumor chemotherapeutic agents, is presently an attractive topics in the study of the optimization of cancer chemotherapy. Furthermore, it has also been approved by the European Agency for the Evaluation of Medicinal Products. ${ }^{12)}$ However, systemic administration of TNF- $\alpha$ was restricted due to its side effects. To use TNF- $\alpha$ for various therapeutic applications, we have created PEG-TNF- $\alpha$ with superior both in antitumor effectiveness and safety.

PEG-TNF- $\alpha$ at a dose of 1000 JRU showed marked hemorrhagic necrosis in S-180 tumors by a single i.v. injection without side-effects (Fig. 1). In mice treated with native TNF- $\alpha$, a little hemorrhagic necrosis was caused at 10000 JRU. However, one of seven mice treated with native TNF- $\alpha$ at this dose died within $24 \mathrm{~h}$, and the remaining mice developed piloerection and tissue inflammation (e.g., erythma) and showed a decrease in body weight. Therefore, we considered that native TNF- $\alpha$ was not appropriate for examining the biological function and the application of therapy by systemic administration.

Figure 2 shows the vascular permeability (VP) induced in various tissues using PEG-TNF- $\alpha$. The VP of tumor blood vessels formed in S-180 tumors was increased at $1-2 \mathrm{~h}$, after an i.v. injection of PEG-TNF- $\alpha$. At $3 \mathrm{~h}$ after the injection of PEG-TNF- $\alpha$, the VP returned to the control-basal level, and it was lower than the control-basal level at $3 \mathrm{~h}$. Furthermore, PEG with high molecular weight (molecular weight $=500000$ ) could accumulate in the tumor tissue as well as PEG with low molecular weight (molecular weight $=$ 12000). On the other hand, the permeability of the vessels in normal tissues, such as the brain, lung, liver, spleen, kidney, and skin, or inflammatory sites in which cotton had been implanted, changed slightly by i.v. injection of PEG-TNF- $\alpha$.

Many researchers reported that TNF- $\alpha$ induces change of endothelial cytoskeletal actin and formation of intercellular gaps with increased permeability to macromolecules. ${ }^{13,14)}$ In addition, we previously reported that endothelial cells cultured in conditioned medium prepared from tumor cells, converted normal endothelial cells to have various character similar to tumor endothelial cells, and these cells had highly sensitivity to TNF- $\alpha .^{15,16)}$ Therefore, the increased permeability of the newly formed vessels in the system at $1-2 \mathrm{~h}$ after the administration of PEG-TNF- $\alpha$ would result from the increasing of the permeability of tumor endothelial cells and the cytotoxicity of PEG-TNF- $\alpha$ on tumor vascular endothelial cells. On the other hand, TNF- $\alpha$ is known to have procoagulant effects on tumor neovasculature, by causing fibrin deposition and localized thrombosis, which, in turn, leads to ischaemic necrosis of tumors. ${ }^{17)}$ Therefore, normalized and decreased permeability at $3 \mathrm{~h}$ would reflect the cessation
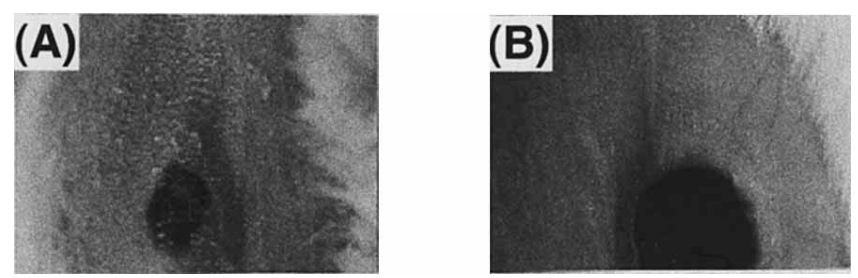

Fig. 1. Hemorrhagic Necrosis Effects of PEG-TNF- $\alpha$

At $7 \mathrm{~d}$ after the tumor inoculation, mice were treated with i.v. injection of the (A) native TNF- $\alpha$ : $10000 \mathrm{JRU} /$ mouse, (B) PEG-TNF- $\alpha$ : $1000 \mathrm{JRU} /$ mouse. Tumor hemorrhagic necrosis was observed $24 \mathrm{~h}$ after the injection by macroscopic observation.
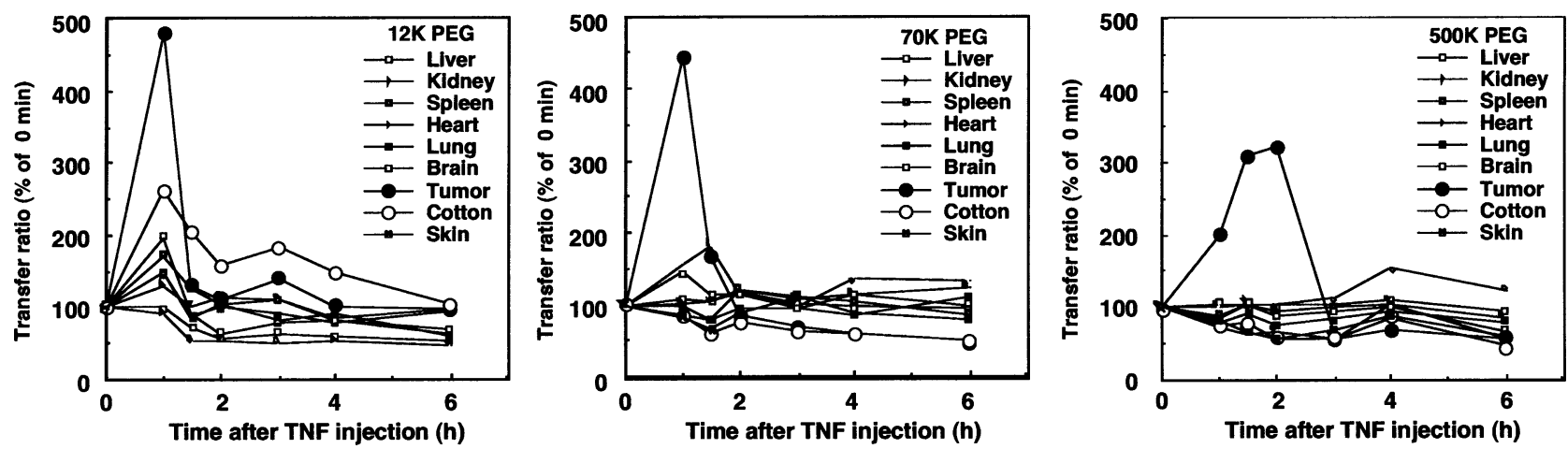

Fig. 2. Vascular Permeability in Various Tissues with PEG-TNF- $\alpha$ Treatment

Mice bearing S-180 tumor were killed at the indicated times after i.v. injection of PEG-TNF- $\alpha$ (500 JRU/ml).Thirty minutes before killing, each mouse was pulsed by an i.v. injection of ${ }^{125} \mathrm{I}$-labeled PEG at a dose of $400000 \mathrm{cpm}$. Control levels without pre-injection of PEG-TNF- $\alpha$ are shown for time 0 . 
of the blood circulation because of the adsorption of fibrinlike substances on the luminal surface of the tumor vascular endothelial cells.

A matter of interest was why PEG with high molecular weight (molecular weight $=500000$ ) showed highest VP at $2 \mathrm{~h}$ when PEG with low molecular weight (molecular weight $=12000$ or 70000 ) could not accumulate in the tumor. The degree of accumulation into the tumor was decided by the balance between the penetration into the tumor tissue from the circulation and the leak from the tumor. Therefore, at $1 \mathrm{~h}$ after the administration of PEG-TNF- $\alpha$, PEG with low molecular weight might accumulate in the tumor easily and accumulate in the tumor without leak. However, PEG with high molecular weight could not penetrate into the tumor. At $2 \mathrm{~h}$ after the administration of PEG-TNF- $\alpha$, PEG with low molecular weight might penetrate into the tumor easily and leak from the tumor into the circulation. On the other hand, PEG with high molecular weight could penetrate into the tumor and accumulate in the tumor without leak.

Recently, many bioactive proteins such as immunotoxin, antibody-toxin conjugates, and cytokine has been attracted a highly expectation for tumor therapy. However, there has been no significant therapeutic response to solid tumors due to insufficient tumor accumulation. Therefore we consider that PEG-TNF- $\alpha$ would overcome these drawbacks. We are now examining the usefulness of PEG-TNF- $\alpha$ for combination therapy using chemotherapeutic drugs or immunotoxin. Thus PEG-TNF- $\alpha$ will open the new way to combination therapy with antitumor agents.

Acknowledgements This study was supported in part by a Grant-in-Aid for Scientific Research (No. 15680014) from The Ministry of Education, Culture, Sports, Science and Technology, Japan, and in part by Health Sciences Research Grants for Research on Health Sciences focusing on Drug
Innovation from the Japan Health Sciences Foundation (KH63124), and in part by Takeda Science Foundation.

\section{REFERENCES}

1) Jain R. K., Sci. Am., 271, 58-65 (1994).

2) Jain R. K., Clin. Cancer Res., 5, 1605-1606 (1999).

3) Carswell E. A., Old L. J., Kassel R. L., Green S., Fiore N., Williamson B., Proc. Natl. Acad. Sci. U.S.A., 72, 3666-3670 (1975).

4) Lejeune F. J., Ruegg C., Lienard D., Curr. Opin. Immunol., 10, 573580 (1998).

5) Eggermont A. M., Schraffordt Koops H., Lienard D., Kroon B. B., van Geel A. N., Hoekstra H. J., Lejeune F. J., J. Clin. Oncol., 14, 26532665 (1996).

6) Skillings J., Wierzbicki R., Eisenhauer E., Venner P., Letendre F., Stewart D., Weinerman B., J. Immunother, 11, 67-70 (1992).

7) Tsutsumi Y., Tsunoda S., Kamada H., Kihira T., Nakagawa S., Kaneda Y., Kanamori T., Mayumi T., Br. J. Cancer, 74, 1090-1095 (1996).

8) Yamamoto Y., Tsutsumi Y., Yoshioka Y., Nishibata T., Kobayashi K., Okamoto T., Mukai Y., Shimizu T., Nakagawa S., Nagata S., Mayumi T., Nat. Biotechnol., 21, 546-552 (2003).

9) Kaneda Y., Yamamoto Y., Kamada H., Tsunoda S., Tsutsumi Y., Hirano T., Mayumi T., Cancer Res., 15, 290-295 (1998).

10) Kamada H., Tsutsumi Y., Yamamoto Y., Kihira T., Kaneda Y., Mu Y., Kodaira H., Tsunoda S. I., Nakagawa S., Mayumi T., Cancer Res., 15, 6416-6420 (2000).

11) Eggermont A. M., Schraffordt Koops H., Lienard D., Kroon B. B., van Geel A. N., Hoekstra H. J., Lejeune F. J., J. Clin. Oncol., 14, $2653-$ 2665 (1996).

12) Eggermont A. M., J. Immunother., 23, 505-506 (2000).

13) Brett J., Gerlach H., Nawroth P., Steinberg S., Godman G., Stern D., J. Exp. Med., 169, 1977-1991 (1989).

14) Goldblum S. E., Sun W. L., Am. J. Physiol., 258, L57-67 (1990).

15) Utoguchi N., Mizuguchi H., Dantakean A., Makimoto H., Wakai Y., Tsutsumi Y., Nakagawa S., Mayumi T., Br. J. Cancer, 73, 24-28 (1996).

16) Kamada H., Tsutsumi Y., Kihira T., Tsunoda S., Yamamoto Y., Mayumi T., Biochem. Biophys. Res. Commun., 268, 809-813 (2000).

17) Nawroth P., Handley D., Matsueda G., De Waal R., Gerlach H., Blohm D., Stern D., J. Exp. Med., 168, 637—647 (1988). 